\title{
АНАЛИЗ ПРИВЛЕКАТЕЛЬНОСТИ РФ ДЛЯ ИНОСТРАННЫХ ТРАНСНАЦИОНАЛЬНЫХ КОРПОРАЦИЙ НА СОВРЕМЕННОМ ЭТАПЕ
}

\author{
(c) 2021 Яворовский Даниэль Олегович \\ аспирант кафедры Финансы и менеджмент \\ Тульский государственный университет, Россия, Тула
}

В статье проанализированы аспекты, которые позволят оценить привлекательность РФ для иностранных транснациональных корпораций (далее ТНК): 1. Динамика прямых иностранных инвестиций в РФ и география стран-инвесторов; 2. Место РФ среди стран по ПИИ; 3. Взаимосвязь ПИИ и показателей внешней торговли.

Практическое применение исследования заключается в возможности его использования при формировании методических основ совершенствования деятельности ТНК в РФ.

Ключевые слова: прямые иностранные инвестиции, транснациональные корпорации, санкции, инвестиционный климат в РФ, положительное влияние прямых иностранных инвестиций, Российская Федерация, иностранный капитал, международное разделение труда.

Для РФ, в силу высокого уровня интегрированности в международные экономикополитические процессы, необходимым для социально-экономического развития страны выступает участие в международномразделении труда и в международном движении капиталов, неотъемлемым атрибутом которых является привлечение транснациональных корпораций и прямых иностранных инвестиций (далее ПИИ) в целом.

Согласно Федеральному закону от 09.07.1999 N 160-Ф3 «прямая иностранная инвестиция приобретение иностранным инвестором не менее $10 \%$ доли, долей в уставном капитале организации, созданной или вновь создаваемой на территории РФ...» [1].

ПИИ имеют следующие преимущества для российской экономики:

- присутствие международного капитала делает РФ привлекательным регионом для ведения бизнеса как среди внешних инвесторов, так и среди отечественных;

- ПИИ способствуют развитию транснациональных корпораций в РФ, которые, с учётом должного законодательного регулирования без возможности образования монополий, усиливают качественную конкуренцию внутри страны, что способствует научно-техническому и социально-экономическому прогрессу страны в целом;

- ТНК и ПИИ в целом обеспечивают не только потребности внутреннего рынка РФ, но и повышают уровень участия РФ в международном разделении труда, что приводит к поддержанию высоких темпов интеграции РФ в мировую экономику.

1. Анализ динамики прямых иностранных инвестиций в РФ и географии странинвесторов.

Динамика прямых иностранных инвестиций в РФ за 2013-2020 гг. представлена на рис. 1.

Исходя из данных видно, что наибольшее снижение притока ПИИ произошло в 20142015 гг. (с 69219 млн. долл. США до 6853 млн. долл. США) что было связано с введением в отношении РФ санкций со стороны стран Запада.

Далее, после незначительного увеличения в 2016 г. до 32539 млн. долл. США началось падение, в 2018 году произошло снижение до уровня 8785 млн. долл. США, что было связано с нарастанием «инвестиционных рисков» российской экономики для иностранных инвесторов.

В 2019 году последовало увеличение до 31975 млн. долл. США с дальнейшим значительным снижением до 9245 млн. долл. США в 2020 году, в свою очередь, данное снижение было обусловлено в большей степени экономическими последствиями пандемии коронавирусной инфекции, чем экономико-политическим положением РФ.

Далее рассмотрим динамику инвестирования в РФ по показателю количества реализованных иностранных проектов, данный показатель позволит нивелировать показатели реинвестирования российского капитала обратно из офшорных зон в виде ПИИ. По данным ЕY в 2020 году география стран, инвестирующих в российскую экономику, представлена следующим образом (см. рис. 2). 


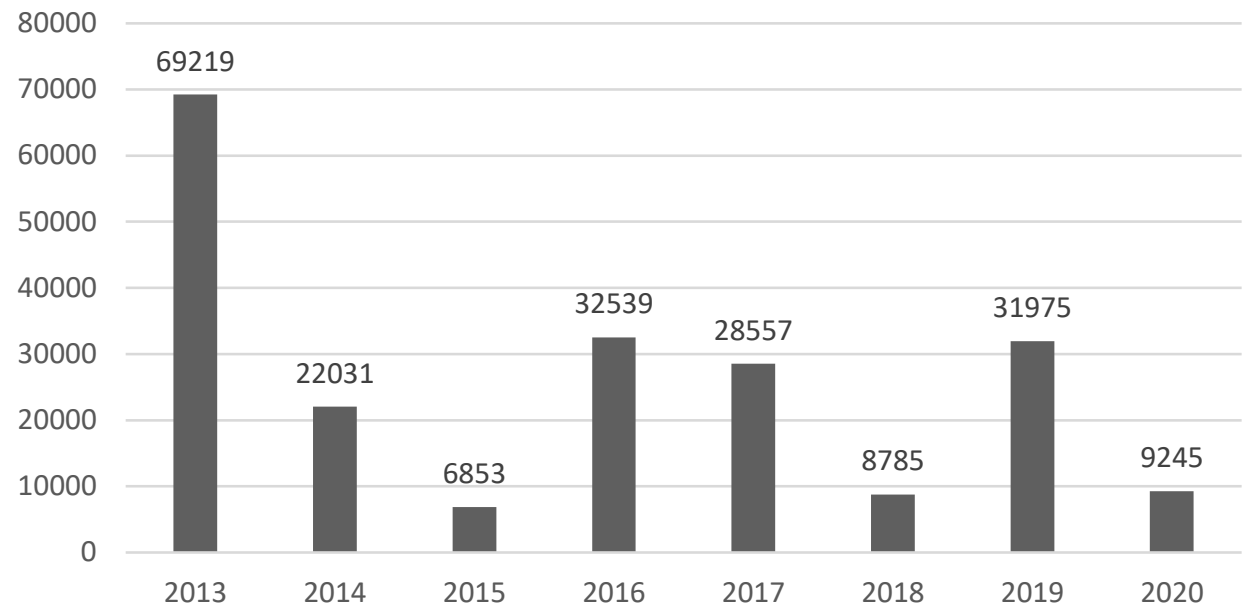

Puc. 1. Динамика прямых иностранных инвестиций в РФ за 2013-2020 гг., млн. долл. США Источник: составлено автором на основе [8]

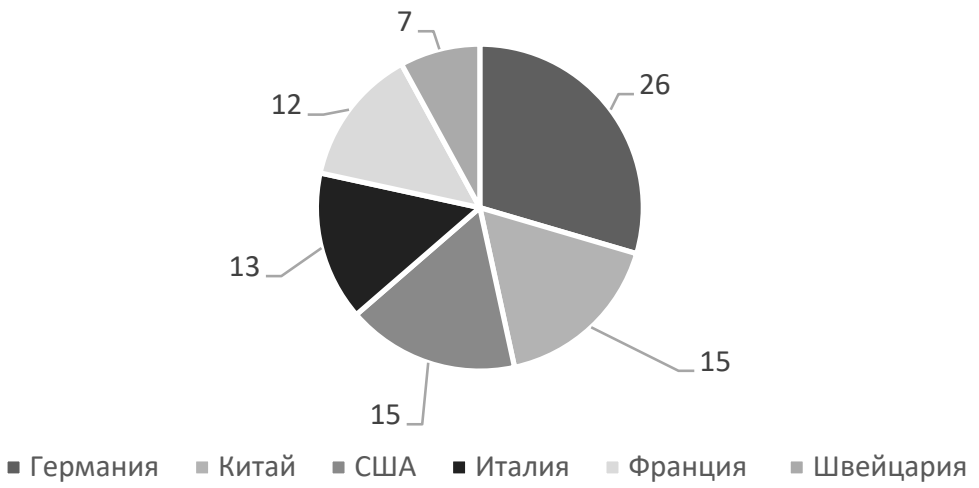

Puc. 2. География основных стран, инвестирующих в российскую экономику в 2020 году (по количеству проектов)

Источник: составлено автором на основе [3]

Как видно из данных: наибольшее количество проектов было реализовано Германией (26 проектов), как наиболее устойчивым иностранным партнёром, в приоритете - инвестиции в АПК.

Далее следует Китай (15 проектов), который в долгосрочной тенденции имеет положительную тенденцию к увеличению ПИИ в РФ. Рассмотрим основные отрасли, в которые осуществляются прямые иностранные инвестиции исходя из осуществлённых проектов, представим их на рис. 3.

Как видно из данных, после 2013 года увеличилось количество иностранных проектов в производственной сфере, в первую очередь - в АПК, обусловлено это развитием сельского хозяйства в силу политики импортозамещения, в связи с чем данная отрасль стала привлекатель- ной для иностранных инвесторов, несмотря на санкционную политику.

Однако, доля стран-санкционеров в общем потоке прямых иностранных инвестиций в РФ значительно снизилась, что отражают данные рис. 4.

Таким образом, после 2013 года значительно снизился как объём ПИИ в целом, так и объём ПИИ от стран-санкционеров (с 57,5 млрд. долл. США до 2,5 млрд. долл. США). Однако, в большой степени данный отток ПИИ ЦБ РФ объясняет не оттоком реальных иностранных инвестиций, а отсутствием реинвестирования со стороны офшорных компаний российского происхождения [2], что в какой-то степени отражает неуверенность отечественных инвесторов в российском рынке. 


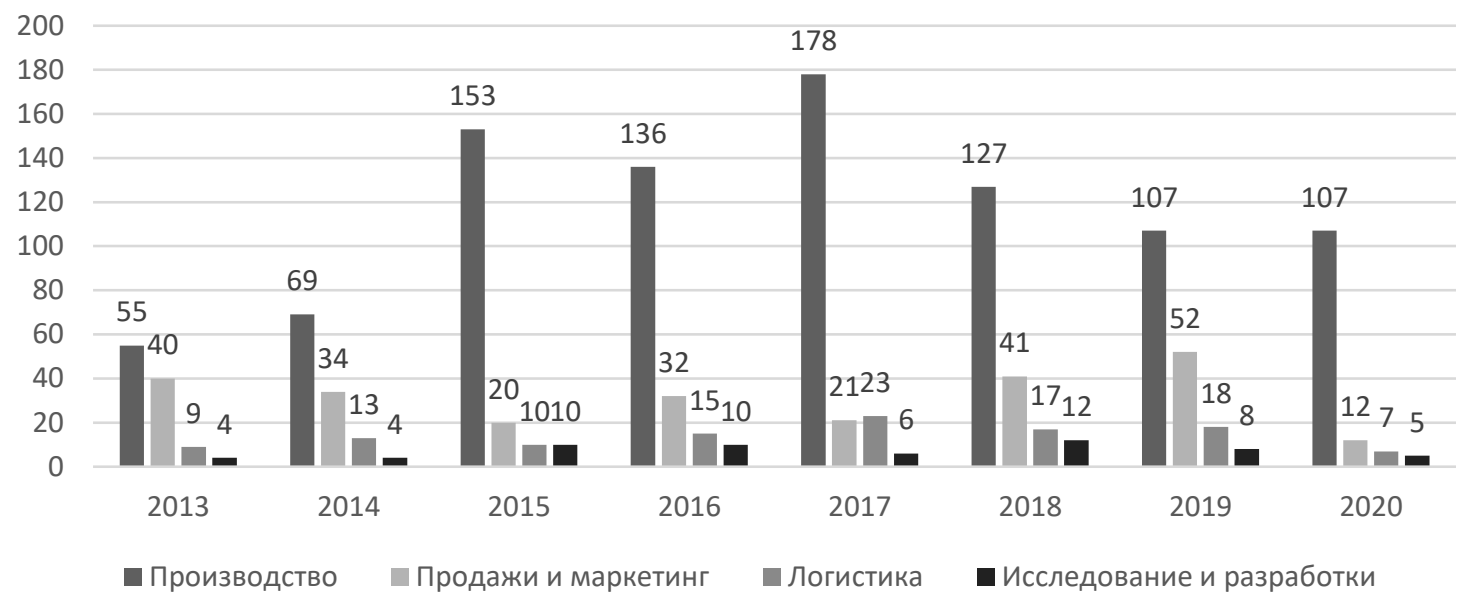

Рис. 3. Основные отрасли, в которые осуществляются ПИИ за 2013-2020 гг. (по количеству проектов) Источник: составлено автором на основе [3,4]

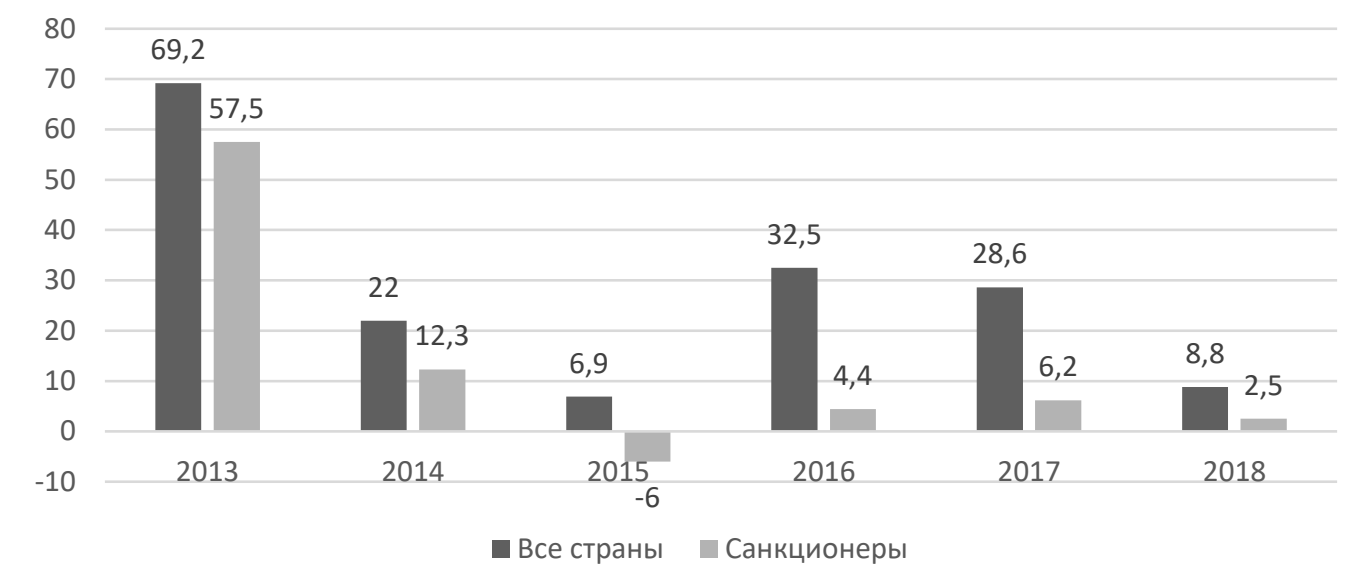

Puc. 4. Объемы чистого поступления ПИИ в РФ от стран-санкционеров и стран в целом за 2013-2018 гг., млрд. долл. США Источник: составлено автором на основе [3]

В связи с этим автором предлагается анализ возможностей стратегического перехода от зависимости РФ от иностранных инвестиций со стороны стран Запада в сторону привлечения иностранных инвестиций от стран Азии, остальных стран БРИКС и ЕАЭС.

Рассматривая региональную составляющую ПИИ в РФ стоит отметить, что Москва стала регионом, наиболее привлекательным для инвесторов, наибольшее количество проектов реализуют инвесторы из Германии, США.

Больше всего проектов в этом регионе принадлежит Франции, Германии и США [3].

Рассматривая перспективы динамики ПИИ в экономику РФ стоит отметить исследование от The European House Ambrosetti с прогнозами ре- зультатов Индекса привлекательности стран на будущее. По данным исследования, РФ и страны Европы в целом, являются рискованными регионами для инвестирования в будущем в силу последствий и возможного обострения кризиса, вызванного пандемией COVID-19.

В рейтинге 2020 года РФ занимает 23 место из 144 стран (по данным ЕY 11-е место среди стран Европы) [6].

Так же важным является рассмотрение деятельности крупнейших ТНК в РФ на 2020 год, так, совокупный объём выручки крупнейших 50 иностранных компаний за 2020 год составил 7 205,3 млрд. руб. [9] (или 101,56 млрд. долл. США по курсу на 31.10.2021 г.) 


\section{2. Место РФ среди стран по ПИИ.}

Выявим место РФ среди стран по ПИИ, проанализируем параметры:

- место РФ в рейтинге стран мира по уровню ПИИ, млн. долл. США (в рейтинге не будут учитываться офшорные зоны);

- выявим место РФ в рейтинге стран мира по уровню ПИИ на душу населения среди стран данного рейтинга (см. табл. 1).

Данные будут анализироваться за 2019 год, данный год отражает значения, исходя из которых можно выявить место РФ без учёта фактора мирового экономического кризиса, вызванного пандемией.

Из таблицы 1 видно, что РФ находится на 25-м месте в рейтинге стран по объёму ПИИ, в свою очередь, в данном рейтинге она находится на 24-м месте по количеству ПИИ на душу населения, что отражает позиции РФ как страну не привлекательную для ПИИ на данный момент, однако, объём ПИИ, равный 69,2 млрд. долл. США в 2013 году говорит о высоком инвестиционном потенциале РФ, который необходимо развивать.

\section{3. Анализ взаимосвязи ПИИ и показате-} лей внешней торговли РФ.

Так же стоит проанализировать взаимосвязь объёмов ПИИ и внешней торговли, за базовое значение в 100\% принят 2013 год (см. рис. 5).
Из данной диаграммы видно, что как экспорт, так и импорт имеют схожие с ПИИ направления, наиболее подчёркнутые в 2015, 2018, 2020 гг.: динамика объёма ПИИ была схожа с динамикой внешней торговли.

Однако, в 2014 году снижение объёма ПИИ было значительно больше, чем снижение объёмов внешней торговли, а в 2018 году при значительном падении ПИИ показатели внешней торговли были выше относительно данных 2017 года.

\section{Заключение.}

Таким образом, в данной статье был проведён анализ привлекательности РФ для транснациональных корпораций на современном этапе, было выявлено, что:

- после 2013 года динамика ПИИ в РФ является нестабильно изменчивой, что связано как с санкционным положением РФ, так и международным кризисом, вызванным пандемией коронавирусной инфекции, однако, на промежутке за 2014-2020 гг. объём ПИИ не достиг и 50\% от показателей 2013 года;

- больше всего иностранных проектов в РФ на 2020 год осуществила Германия (26 проектов) и Китай (15 проектов);

- наибольший интерес для иностранных инвесторов представляют производственные

Таблица 1. Место РФ в рейтинге стран мира по уровню ПИИ

\begin{tabular}{|c|c|c|c|c|c|c|}
\hline 1 & 2 & 3 & 4 & 5 & 6 & $7=3 / 6$ \\
\hline $\begin{array}{c}\text { Рейтинг стран } \\
\text { мира по уров- } \\
\text { ню ПИИ }\end{array}$ & Страна & $\begin{array}{c}\text { Размер ПИИ, } \\
\text { млн. долл. } \\
\text { США }\end{array}$ & $\begin{array}{c}\text { Рейтинг стран } \\
\text { по уровню } \\
\text { ПИИ на душу } \\
\text { населения }\end{array}$ & Страна & $\begin{array}{c}\text { Численность } \\
\text { населения, } \\
\text { млн. чел. }\end{array}$ & $\begin{array}{c}\text { Размер ПИИ } \\
\text { на душу насе- } \\
\text { ления, долл. } \\
\text { на чел }\end{array}$ \\
\hline 1 & США & 258,390 & 1 & Израиль & 9,217 & 2255,46 \\
\hline 2 & Китай & 203,492 & 2 & Австралия & 25,690 & 2372 \\
\hline 3 & Германия & 105,277 & 3 & Германия & 83,240 & 1264,74 \\
\hline 4 & Бразилия & 88,324 & 4 & Австрия & 8,917 & 1261,19 \\
\hline 5 & Австралия & 60,951 & 5 & Канада & 38,010 & 1194,85 \\
\hline 6 & Франция & 59,849 & 6 & Испания & 47,350 & 943,33 \\
\hline 7 & $\begin{array}{l}\text { Великобрита- } \\
\text { ния }\end{array}$ & 58,650 & 7 & Франция & 67,390 & 888,10 \\
\hline 8 & Канада & 45,416 & 8 & $\begin{array}{l}\text { Великобрита- } \\
\text { ния }\end{array}$ & 67,220 & 872,51 \\
\hline 9 & Испания & 44,666 & 9 & США & 329,500 & 787,18 \\
\hline 10 & Индия & 42,117 & 10 & Италия & 59,550 & 518,95 \\
\hline$\ldots$ & $\ldots$ & $\ldots$ & $\ldots$ & $\ldots$ & $\ldots$ & $\ldots$ \\
\hline 24 & Филиппины & 9,802 & 24 & Россия & 144,100 & 60,96 \\
\hline 25 & Россия & 8,784 & 25 & Индия & 1380 & 30,51 \\
\hline
\end{tabular}

Источник: составлено автором на основе $[7,10]$ 


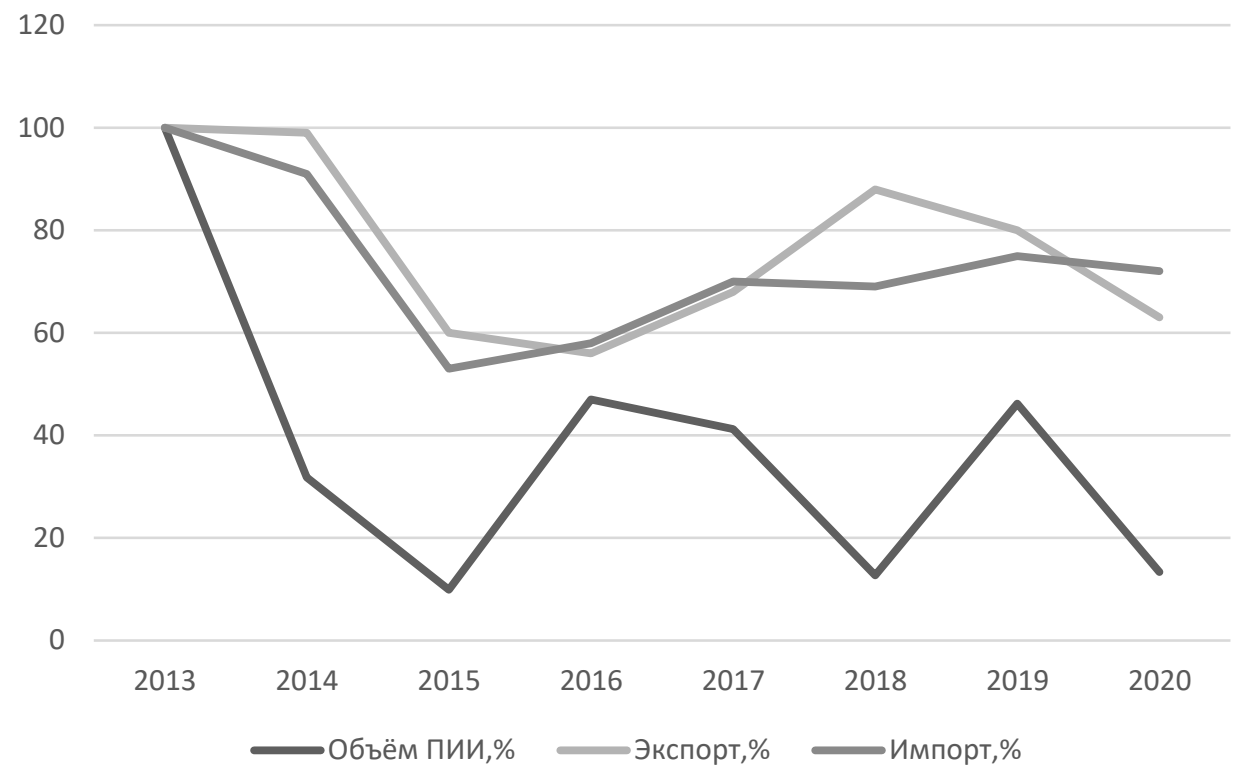

Puc. 5. Отношение показателей ПИИ и внешней торговли в 2013-2020 гг. (в \% к 2013 г.) Источник: составлено автором [5,8]

проекты (107 проектов за 2020 год относительно 55 проектов за 2013 год);

- по данным ЕY РФ находится на 11-м месте по инвестиционной привлекательности среди 20 стран Европы;

- рассматривая место РФ среди стран по ПИИ было выявлено, что что Россия находится на 25-м месте в рейтинге стран по объёму ПИИ и на 24-м месте по количеству ПИИ на душу населения, что отражает позиции РФ как страну не привлекательную для ПИИ на данный момент;

- наблюдается взаимосвязь между динамикой ПИИ и динамикой внешней торговли.

\section{Библиографический список}

1. Федеральный закон от 09.07.1999 N 160-ФЗ (ред. от 02.07.2021) «Об иностранных инвестициях в Российской Федерации» (с изм. и доп., вступ. в силу с 24.08.2021)

2. Аналитики ЦБ объяснили трёхкратный обвал иностранных инвестиций [Электронный ресурс] // Режим доступа: https://www.rbc.ru/economics/13/05/2019/5cd981989a7947252f589b47

3. Исследование инвестиционной привлекательности стран Европы в 2020 году [Электронный ресурс] // Режим доступа: https:/www.ey.com/ru_ru/attractiveness/21/european-attractiveness-survey-2021-russia

4. Казанцев С.В. Санкции и прямые иностранные инвестиции: ущерб для РФ и стран-санкционеров. Мир новой экономики. 2020;14(1):44-53. https://doi.org/10.26794/2220-6469-2020-14-1-44-53

5. Помесячная динамика экспорта и импорта товаров Январь 2013-Август 2021 [Электронный ресурс] // Режим доступа: https://dcenter.hse.ru/mirror/pubs/share/direct/519650695.pdf

6. Рейтинг привлекательности стран: 2020 [Электронный ресурс] // Режим доступа: https://roscongress.org/ materials/reyting-privlekatelnosti-stran-2020/

7. Рейтинг стран мира по уровню прямых иностранных инвестиций [Электронный ресурс] // Режим доступа: https://gtmarket.ru/ratings/foreign-direct-investment-index

8. Статистика внешнего сектора [Электронный ресурс] // Режим доступа: https://old.cbr.ru/statistics/macro_ $\mathrm{itm} / \mathrm{svs} /$

9. 50 крупнейших иностранных компаний в РФ [Электронный ресурс] // Режим доступа: https://www.forbes.ru/ biznes/441733-50-krupnejsih-inostrannyh-kompanij-v-rossii-2021-rejting-forbes

10. Place explorer [Электронный ресурс] // Режим доступа: https://datacommons.org/place/country/RUS?utm_med ium=explore \&mprop=count \&popt=Person \&hl=ru 